\title{
Vibration-Assisted Ball Burnishing
}

\author{
Ram ón Jerez-Mesa ${ }^{1, * \mathbb{C}}$, Jordi Llumà ${ }^{2} \mathbb{D}$ and J. Antonio Travieso-Rodríguez ${ }^{1} \mathbb{D}$ \\ 1 Department of Mechanical Engineering, Universitat Politècnica de Catalunya, 08034 Barcelona, Spain; \\ antonio.travieso@upc.edu \\ 2 Departament of Material Science and Engineering, Universitat Politècnica de Catalunya, \\ 08034 Barcelona, Spain; jordi.lluma@upc.edu \\ * Correspondence: ramon.jerez@upc.edu
}

check for

updates

Citation: Jerez-Mesa, R.; Llumà, J.; Travieso-Rodriguez, J.A.

Vibration-Assisted Ball Burnishing. Encyclopedia 2021, 1, 460-471.

https://doi.org/10.3390/

encyclopedia1020038

Academic Editors: Krzysztof Kamil Żur, Raffaele Barretta, Ramesh Agarwal and Giuseppe Ruta

Received: 17 May 2021

Accepted: 8 June 2021

Published: 11 June 2021

Publisher's Note: MDPI stays neutral with regard to jurisdictional claims in published maps and institutional affiliations.

\section{Copyright: (c) 2021 by the authors.} Licensee MDPI, Basel, Switzerland. This article is an open access article distributed under the terms and conditions of the Creative Commons Attribution (CC BY) license (https:// creativecommons.org/licenses/by/ $4.0 /)$.
Definition: Vibration-Assisted Ball Burnishing is a finishing processed based on plastic deformation by means of a preloaded ball on a certain surface that rolls over it following a certain trajectory previously programmed while vibrating vertically. The dynamics of the process are based on the activation of the acoustoplastic effect on the material by means of the vibratory signal transmitted through the material lattice as a consequence of the mentioned oscillation of the ball. Materials processed by VABB show a modified surface in terms of topology distribution and scale, superior if compared to the results of the non-assisted process. Subgrain formation one of the main drivers that explain the change in hardness and residual stress resulting from the process.

Keywords: ball burnishing; acoustoplasticity; vibration-assistance; surface integrity; surface topology

\section{History: From Ball Burnishing to the Vibration Assisted Version of the Process}

This Encyclopedia entry deals with the main aspects and details related to the ball burnishing process assisted with a vibratory signal (namely, vibration-assisted ball burnishing or VABB henceforth). Ball burnishing is based on deforming plastically with a preloaded sphere the irregularities of a surface that has been previously machined, so that its roughness or texture features are reduced while hardness is increased due to cold deformation (Figure 1a). However, this interaction is three-dimensional and is very much influenced by the friction between the ball and the material. The main physical vector to achieve that deformation is the preload force with which the ball is preloaded and the number of passes by which the target surface is covered. By assisting the process with vibrations, a vibratory component of the force $F_{v}$ is overlapped to the preload $F_{p}$, resulting in the overall vibratory burnishing force $F_{b}$, as shows Figure $1 \mathrm{~b}$.

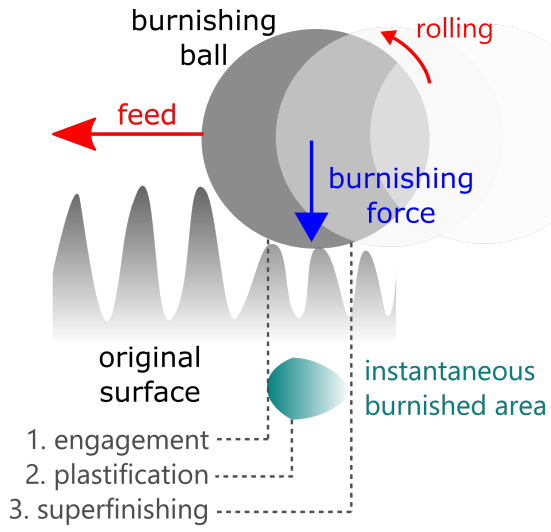

(a)

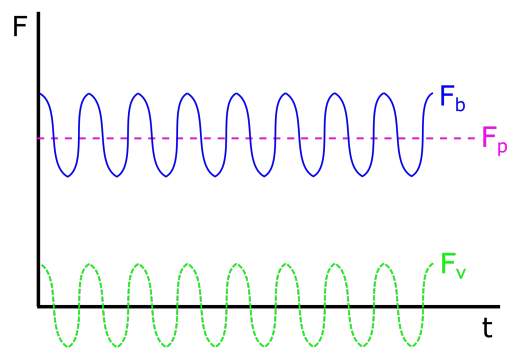

(b)
Figure 1. (a). General overview of a vibration-assisted ball burnishing process. (b). Components of the burnishing force $\left(F_{b}\right)$. 
The process must be understood as the upgrade of a classical operation complemented with an extra layer that introduces new dynamics and modifies the way the tool interacts with the material of the target surface. The oldest references related to ball burnishing itself refer to the processing of certain parts of the automobilistic industry in the sixties [1]. The process was described simply as a means whereby the motion of a ball or roller displaces the peaks of the surface roughness profile into the valleys. Today, we know that this apparently simple description does not account for the very complex mechanisms that are put at stake when this kind of process is deployed to provide a certain workpiece with a desired finishing state. The phenomenon whereby the material surface is modified is more likely to be compared to how the wavy surface of calm waters on the sea are smoothly moved by the effect of the wind, changing their direction, but keeping a very similar pattern all the way through.

Ball burnishing has been often cited because of its direct effects on the surface texture. The actual description of this modification can be described as a triplet:

- $\quad$ The surface texture features are reduced to a lower scale.

- The material that composes the surface is redistributed to a Gaussian distribution of heights.

- If enough plastic deformation is exerted, the surface features can be reoriented along the ball burnishing direction.

As the last of the described effects is only observed if the proper force and number of passes are combined to obtain the desired surface finishing, it could be said that the original explanation of ball burnishing in which material peaks were introduced in the valleys is not totally accurate.

Besides the topological effects of the process, the material also embodies other transformations that define its state after ball burnishing. Specifically, by experiencing cold deformation, the material is ultimately cold-hardened, providing the final workpiece with a reinforced outer layer with enhanced performance. Furthermore, a higher compressive residual stress profile is formed in the subsurface layers of the material. This change of mechanical state of the material is also often observed in the change of the microstructural state of the outer layers of the material itself, if a cross-section of the processed surface is observed.

The assistance of ball burnishing in the mid-twentieth century responded at the time to an extended trend in the manufacturing innovation ecosystem based on providing classical operations with extra functions that enhanced the outputs of these processes. This is how hybrid processes such as vibration-assisted machining [2] or laser-assisted ball burnishing [3] were born and are still today used in many manufacturing companies. Specifically, VABB was brought into play into the finishing operations industry, incorporating a vibratory movement to the burnishing ball simultaneous to its rolling over the surface irregularities while it runs the programmed trajectory. VABB was for the first time reported during the 1970s, designed as ultrasonic burnishing. It was assisted by 41.5 $\mathrm{kHz}$ vibrations and a variable amplitude from 5 to $10 \mu \mathrm{m}$ [4]. The first detailed academic bibliography dealing with VABB dates from the 1980s [5], although some references could be found in previous years focusing on the comparison of the friction coefficient, wear rate or load bearing capacity of VABB-treated surfaces with regards to surfaces finished through other processes such as boring, grinding or even simple ball burnishing. However, these references did not focus on the phenomenology behind the results or their relation with the descriptive parameters of the surfaces themselves.

This entry is divided in three sections. The first describes the overall results observed on different materials after VABB. The second offers an insight into the physical origins of the vibratory assistance. Furthermore, finally, the hardware and physical systems reported in literature are explained. 


\section{Effects of VABB on Materials}

In general, the affectation of surfaces after VABB can be described very similarly to the one resulting from the conventional process, namely as a comprehensive effect on the material at the surface on the topology or roughness, microhardness and residual stress with a higher affectation of the surface. The references that are included in this section show that VABB does not necessarily enhance all properties simulatenously, hence the importance and need to know the process and decide whether to use it or not and to distinguish its adequateness according to the desired surface characteristics.

The first results reported after VABB by Marakov (1973) [4] found a relevant interaction between the vibration amplitude and the obtained surface roughness. Indeed, the anticipated positive effect of higher force values on the resulting surface roughness was only observed on those mild steel specimens treated with a $2 \mu \mathrm{m}$ amplitude. A reduction in the friction coefficient between the burnishing ball and the recipient material was also reported in those conditions. Later on, Pande and Patel (1984) [5] reported results on low-frequency $(10$ to $70 \mathrm{~Hz}$ ) vibratory burnishing in contrast to the high-frequency assited process. Results provided evidence for an inverse interaction between the preload and the amplitude of the assistance, obtaining lower surface roughness values for amplitudes lower than $0.5 \mu \mathrm{m}$. They also found that the vibration-assistance was remarkably positive with regards to the residual hardness obtained after the tests, as an assistance with $60 \mathrm{~Hz}$ vibration allows the lowest preload to be successful in increasing these values compared to the unassisted process.

No other relevant research sources about ultrasonic burnishing can be found until the 2000 's, when new references to the process start to be found on different materials. Bozdana et al. (2005) [6] applied the process on Ti-6Al-4V specimens assisted with $20 \mathrm{kHz}$ and 6.75 $\mu \mathrm{m}$ vibration on a milling machine. It was proved that there is a critical value from which surface roughness is harmed when the VABB process is applied, and should be defined. For the ultrasonic process, that point is at a much lower preload level, probably because transient softening due to the transmission of the vibratory signal through the material favours the in situ plastic deformation. Consequently, the effects of vibration-assistance can fire back by deforming excessively the material at the surface, and should be carefully selected [7]. However, residual stress and hardness results were much more promising, as the ultrasonic process resulted in higher values with half the preload required for the non-assisted process. Therefore, it can also be stated that the process seems not to be neatly positive in affecting the surface under different perspectives, i.e., some aspects might be improved while others are harmed.

The references related to VABB since the 2010s have increased considerably, including few references applied on a lathe on different materials [8,9]. The VABB applied on milling machines clearly dominates the state of the art in this sense. A 2-kHz assistance was reported to improve the surface roughness of AISI 1038 [10] and EN AW 7078 [11] with regards to the non-assisted process (NVABB), although the results in terms of microhardness were questionable. Extensive experimental research has been performed to analyze the impact of VABB on different ball-end milled surfaces of AISI 1038 [12], Ti-6Al-4V [13], nickel-based Udimet 720 alloy [14] and AISI 306 [15]. In all cases, following the same research pattern by applying Taguchi experimental design, the authors conclude that VABB proves its effectiveness to modify effectively the surface topology of all surfaces, and redistributing the material to a Gaussian state. Other works on the AISI 316L steel has also been conducted [16]. Furthermore, the threshold value of the preload from which the surface is harmed was identified, being different for each of the tested materials. It was also noted that it seems that in applying the VABB process, the effect of the original surface is of upmost importance, as it defines the improvement potential of the surface itself. The authors conclude that the vibration-assistance should only be selected to improve surface topology if the original Sq descriptor of the surface is $5 \mu \mathrm{m}$ or less; but on the other hand that topological improvement can be accompanied with a lower level of compressive residual stress [13]. 
The nanoscopical level also shows information about how the material at the surface is modified after VABB. It has been found that the process succeeds in refining the grain structure at the subsurface on many alloys such as aluminum 6061 [17] or AISI 1045 [18], and is even able to promote the phase transformation in materials such as Ti-6Al-4V [19], or austenitic metastable AISI 306 [15] (by forcing the generation of martensite by cold plastic strain) [20]. This translates into a higher residual hardening and stress. In biocompatible materials, investigators have succeeded in generating subsurfaces that favour cell adhesion, and can, therefore, increase the biocompatibility of materials [21]. Grain refinement on $17-4 \mathrm{PH}$ stainless steel surfaces also resulted in a wear and corrosion resistance of the material, compared to the conventional unassisted version of the process [22]. In all cases, new research seems to show that the correct direction to continue with investigations about VABB is to consider how the microstructure is changed.

\section{Pros, Cons and Capabilities of VABB}

The development of the VABB throughout the years and the very positive results obtained in research have positioned VABB as a potential process to be implemented in many kinds of industries. Although no works comparing VABB with other finishing processes have been reported, its non-assisted counterpart has proved to be superior in terms of residual stress and topological improvement if compared to it direct competitors, such as laser shock peening or shot peening [23]. If it is assumed that VABB is an upgrade of NVABB, the general superiority of VABB with regards to other competitive finishing processes can be inferred by extension.

The capabilities of the process do not only result from the effects on the material itself, but also the ease with which it can be introduced in a manufacturing routine through numerical control has to be highlighted. The authors work, for instance, with a company that is substituting their manual polishing for moulds for the automotive industry by this automatised process. The introduction of VABB in their routine not only has reduced the processing time of each part but has also allowed the owners of the company to exploit their machine tools overnight with the automatised process.

Companies from the aeronautical industry are also eligible to implement VABB in their routines. This industry is on the search of processes that can help them improve the conditions of selective surfaces that are subjected to fatigue stress. The target of VABB does not have to be a whole surface but specific sectors of the part that engineers have identified as critical, what makes the process still more interesting in comparison with other ones that cannot be so selective, such as sand blasting or laser shock peening.

The process also demonstrates disadvantages, as the equipment required to execute it is based on an external circuit that has to be branched to the VABB tool so that it can work. This wiring could be a handicap to automatise the process, or at least could be a conundrum for production engineers willing to guarantee the security of the process itself. Furthermore, it would require more space to install the external power circuit.

Theoretical models of VABB are scarce but have arisen the fact that the simultaneous improvement of texture and residual stress cannot always be possible with VABB [24]. The solution to that is to adjust very thoroughly the burnishing parameters to achieve this simultaneous effect. Therefore higher preprocessing and preparation time can also be cited as a drawback of the process and introduces a new challenge for industries willing to implement it in their routines.

The authors consider that these disadvantages cannot overshadow the evident advantages of the process itself, as it has been presented above, not only in practical terms but also in material modification and performance after being finished through VABB. It is true that the time required to define a correct selection of VABB parameters (explained in subsequent subsections) is long, but it can definitely pay off later on once the process is effectively implemented in the manufacturing routine of the adopters. 


\section{Physical Principles behind VABB}

Originally, the introduction of vibration assistance was brought into the industry just by following the hypothesis that a vertical movement of the burnishing ball, simultaneous to its longitudinal feed movement, could have a similar effect on the material as if successive impacts were applied on the surface, i.e., due to a hammering effect on the material that composed the interface of the workpiece. The results obtained after VABB, and that shall be described in the next section, evidence that the process leads to different results compared to its original counterpart. However, it is not clear today what the phenomenological explanation is that accounts for the process results. This is caused by the fact that it is impossible to visualize how the actual engagement of the ball with the surface material is modified due to the vibratory movement, and how stress is transmitted into the material subsurface layers.

Regardless of this limitation, research during the last few decades has allowed the scientific community to obtain new insights of the technology itself. The evidence found demonstrate that there are two main causes whereby VABB offers different results with regards to it conventional counterpart, namely:

1. Due to the fact that it activates the acoustoplastic effect on the material.

2. Due to the fact that it modifies the engagement dynamics of the ball and the material during rolling.

\subsection{The Acoustoplastic Effect}

Acoustoplasticity consists of the decrease in the quasi-static stress to which a material must be subjected to be plastically deformed by means of overlapping a vibratory signal over the physical force that causes that strain. As ball burnishing is based on plastic deformation, it is, therefore, eligible to be enhanced by this effect. Acoustoplasticity was reported for the first time by Blaha and Langenecker in 1955 [25] on pure zinc crystals radiated by a $800-\mathrm{kHz}$ ultrasonic wave. Hence its alternative designation as Blaha effect. It was proved later on that it can be universally observed in metals [26], although the degree of affectation varies according to the properties of the materials. For instance, the higher the acoustic impedance and the higher elastic modulus of a material, the higher its sensitivity to be affected by acosutoplasticity [27]. The acoustoplastic effect has proven to be independent of the vibration frequency [28] but its effects vary according to the vibration amplitude although the source of this influence is not clear [29,30].

The consequences of acoustoplasticity are dual because it can cause residual softening but also residual hardening [31]. Gindin et al. (1972) [32] concluded that the residual hardening is only present if an intensity threshold is surpassed. This observation is interesting to justify the assistance of ball burnishing with vibrations because it could facilitate plastic strain during the process while provoking a residual hardening of the target surface.

Despite the fact that acoustoplasticity has been experimentally observed on a high variety of materials, its actual physical source is still controversial. The conundrum is based on the fact that there is no agreement on whether acoustoplasticity has an intrinsic or extrinsic causes, i.e., whether it is provoked by a reaction inside the material's microstructure to the external source of vibrations, or by the increase of the power deployed into the system without change of the material behaviour. Ultimately, the reader shall find that acoustoplasticity has a polyhedral nature.

The intrinsic approach to the issue is based on the hypothesis that ultrasonic energy was preferentially absorbed by defects in the metal lattice (e.g., dislocations or grain boundaries). The intrinsic approach is based on the idea that these defects are actual responsible for the mechanisms of plastic deformation, hence its potential to explain why acoustoplasticity works and can be observed at a macro level. This idea was deffended by Blaha and Langenecker [25,33]. Later on, Mason (1955) [34] argued that as the lattice defects absorb the vibratory energy, dislocation mobility is enhanced and this effect allowes the metal to deform under lower loads. Based on this theory, Gindin et al. (1972) [32] justified 
the residual hardening observed on materials deformed through acoustoplasticity because of dislocation loops on the material lattice and the new stable vacancies accumulated in it. Pohlman and Lechfeldt (1966) [35] reinforced this intrinsic approach by observing that the force drop during ultrasonic strain was only observed during the plastic strain phase, and not in the elastic one, as plastic deformation mechanisms are related to metal lattice dynamics. Langenecker (1966) [31] proposed that the ultrasonic energy at lattice defects caused a microheating effect, facilitating the material strain. Imperfections in the metal lattice tend to look for minimal energy positions, provided that a certain threshold value of energy is exceeded. Therefore, they defended that the increase in dislocation mobility must be a thermally activated process, meaning that acoustoplasticity would only happen if a certain activation energy was surpassed. Although they contributed to the understanding of acoustoplasticity, intrinsic theories could explain why other mechanisms related to energy absorption by lattice defects such as resonance or hysteresis based on ultrasonic do not have the same effect as acoustoplasticity, and, therefore, evidenced limitations.

Chronologically simultaneous were the works undertaken by Nevill and Brotzen (1957) [36], who defended extrinsic theories. They proposed that the observed stress decrease through acoustoplasticity was independent of the temperature. Therefore, they explained the acoustoplasticity phenomenon as a result of macroscopic superposition of steady and oscillatory stresses. Kirchner et al. (1985) [37] developed an extrinsic model by a set of experiments performed with a universal testing machine on aluminium specimens, by programming different overlapped sinusoidal forces on the deforming forces at low, medium and high frequencies. However, as this model lacked total correspondence with experimental observations, the role of internal friction was introduced eventually in the system, assuming its responsibility for the equilibrium of forces that need to be satisfied during the quasi-static deformation of a material $[38,39]$. Still, results were not exactly consistent with experimental observations. Therefore, a purely extrinsic approach to the topic did not seem to be sufficient to explain satisfactorily the sources of acoustoplasticity.

The recent advances in microstructural analysis has allowed researchers to revive the discussion about the roots of acoustoplasticity. Vickers microindentation tests performed with a vertical 30-kHz vibrating indenter were conducted in 2011 by Siu et al. on pure aluminium [40], copper and molybdenum [41] proved that the diamond-shaped indentations for the ultrasonic-indented prints were bigger. This confirms a decrease in the hardness experienced by the material during the application of the ultrasonic plastic deformation. It was confirmed later on that this is due to dislocation annihilation [42] promoted by acoustoplasticity, as the positive vibratory cycle promotes dislocation travel to further places, and the negative cycle slows them down to favour that annihilation. Furthermore, SEM observations evidenced that subgrains are formed after indentations performed with a vibration assistance unlike the results evidenced by specimens indented quasi-statically. That explains residual hardening, as subgrains act as secondary boundaries which increase the required energy to move the dislocations because of the increase in heterogeneity in the direction of slipping planes inside the material lattice. That is associated to hardness increase. On the other hand, that strain hardening is highly unbalanced, what derives in higher residual stress [43].

This explanation that combines dislocation annihilation and subgrain formation by means of acoustoplasticity is actually a fusion of extrinsic and intrinsic theories and is so far the explanation that accounts more accurately for acoustoplasticity. Indeed, neither is acoustoplasticity just a stress addition effect, nor the preferential absorption of vibratory energy by lattice defects. It also supports the non-dependence of the softening results on the frequency [44]. In contrast to that, it seems tha the vibratory amplitude does influence the residual hardening results, as observed in 2015 by Cheng et al. (2015). In fact, this author remarked that the effect of acoustoplasticity is only conspicuous if an amplitude threshold value is surpassed [45]. This result is in line with the mid-20th century acoustoplasticity experiments explained above. 


\subsection{Modification of the Engagement Dynamics Ball-Material}

The previous subsection has shown that the usefulness of vibration-assisted ball burnishing can be justified with the resources that material science is able to deliver. However, focusing on how the material is modified during deformation assisted with a vibration is not enough to explain why ball burnishing happens. Indeed, there is a second relevant mechanism that explains the change of the effects of ball burnishing due to vibrations related to the fact that the interaction of both solids changes as the ball moves or is moved by a dynamic mechanism. That is, the frictional behaviour of the ball and the material must be of great importance to the results, because it is that contact that enables vibratory transmission.

The described effect has been formulated guided by the extensive experimental observation and out of intuition, as it is not possible to actually see what is the interaction between the ball and the surface during the process. It is still more complicated to visualise what the impact of the vibratiory movement is. For this reason, researchers are incipiently working on finite element model that can show in detail what are these interactions and predict eventual results of the process [46]. Shen et al. (2019) have developed a 3D FE model of VABB that shoes that a forced vibration overlapped on a static force (preload), the alternative force can be understood as a dynamic hammering that derives in a higher penetration of the residual stress. They also highlight that the compressed layer will be saturated at a certain static load and that, therefore, the room for improvement after VABB is not infinite.

This line should be higher explored in the future, to better understand the dynamics of the process. Lacking the possibility of actually observing the interphase between ball and surface, numerical models are a clear alternative to understand the phenomenology of the process and know how the engagement of the ball and the material occurs during VABB.

\section{Equipment to Deploy of Vibration-Assisted Ball Burnishing}

To date, in this text, VABB has been explained as a single process. However, there are numerous ways whereby the vibrations can be introduced in the system and how they are technically deployed:

1. Vibrators based on electromagnets that were designed to produce a certain peak-topeak force during their movement, and that were attached to the machine where they were executed [5]. This kind of systems are the oldest ones and their specific functioning has not been reported in the bibliography with enough detail as to understand how the system works.

2. Alternative deflection of plates subjected to variable magnetic fields, as shown in Figure 2a. The source of vibration is caused by the positive and negative deflection of the thin plate to which the ball is attached as a consequence of a variable magnetic field created by a coil excited with an external circuit. Therefore, these kind of systems have a true limitation of the frequency at which they can work because the thin plate is not able to follow an excessively high frequency for reasons of inherent stiffness. For this reason, these kinds of systems are not capable to arrive to the ultrasonic level. Although these systems exists at the experimental level, they cannot be found in the industrial level. However, their importance lies in the fact that the results that can be obtained by them can be used to establish a comparison point with the VABB process assisted with ultrasonic frequencies. For instance, Gomez-Gras et al. (2015) [47] reported asuccessful $2.1 \mathrm{kHz}$ assisted system that proved to introduce the acoustoplastic effect in the system and allowed the researchers to ulteriorly report very positive effects of the process itself [10].

3. A sonotrode attached to a piezoelectric stack, which forces vibration by the expansion and contraction of a sonotrode thanks to an external power circuit that transmits an oscillatory signal $[48,49]$. This kind of systems is shown in Figure $2 b$. 


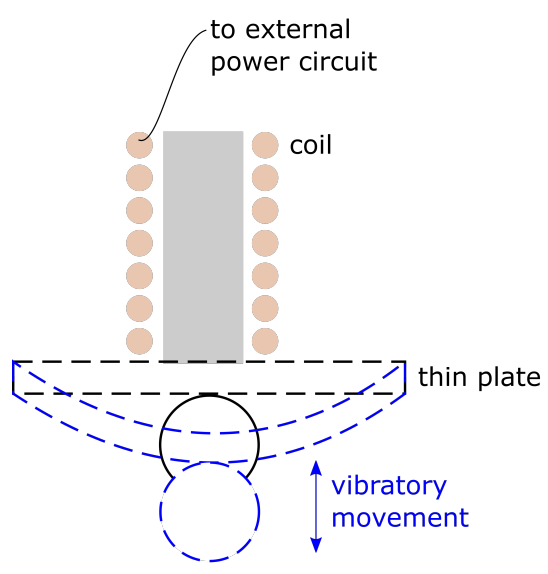

(a)

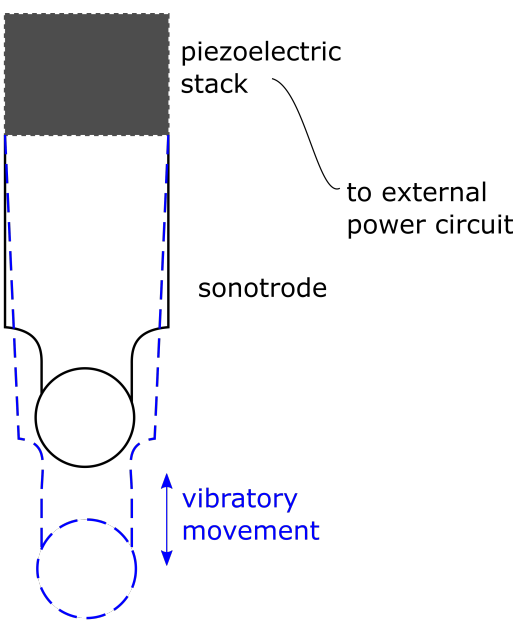

(b)

Figure 2. Schematic representations of VABB systems. (a). Systems based on deflective plates. (b). Systems based on sonotrode deformation.

The readers must take into account that all the described systems are based on the general idea of precharging the burnishing tool on the surface and then activating the vibratory system. As a consequence, the free oscillatory movement of the plate or sonotrode are restricted. That is, their normal free movement when they are excited without contact with the workpiece is dampened according to the elastic properties of the material that is being treated. As a consequence, the actual mechanical system that represents VABB is evidently complex and must be understood as a version of how the tool moves and vibrates when it is not constricted. For this reason, the correct functioning of VABB equipment should be checked to confirm that the vibratory signal originated by the vibrating tool is successfully transmitted though the material lattice. Direct dynamometric measurements or acoustic emission sensors could do the job if installed properly [48]. The challenge in this case would be to have accessibility to acquisition systems that have a high enough sampling frequency to reconstruct the signal, if the assistance is ultrasonic.

\section{$V A B B$ Conditions}

The numerous factors that can be chosen to apply the process makes it very easy to design a particular application of VABB for a certain material. Of all these parameters, some of them are directly related to the productivity of the process and the other are responsible for its technical implementation and the actual effectiveness of VABB on the target material. The reader shall find a description of all of the in the next paragraphs:

1. Preload $F_{p}$. This parameter is related to the static force that the VABB tool exerts once it makes contact with the target surface and is further pressed on it. For a correct execution of the process, it should be the mean value of the actual burnishing force $F_{b}$. Its definition is the same one for the VABB process both executed on a milling machine or a lathe.

2. Number of passes $n_{p}$. It makes reference to the number of times the process is applied on the target material. Along with the preload, it defines the degree of plastic deformation applied on the surface after the whole operation is performed.

3. Trajectories. Refer to the path that the burnishing ball follows to cover the target surface. In VABB processes programmed on a milling machine, these trajectories can either overlap, or not, and also refers to an eventual change of the feed movement along the $\mathrm{x}$ or the $\mathrm{y}$ axis. In lathe operations, it cannot be changed, as in this case VABB can be assimilated with a turning strategy that has no room for change. It has also been observed that the directionality of the passes can define the orientation of the final texture and residual stress anisotropy [12]. 
4. Lateral offset $b$. Separation between adjacent burnishing lines to cover the target surface. This value corresponds to the feed in a lathe VABB operation and the actual coordinate that the ball is laterally displaced between one pass and the next one in a milling VABB routine. It must be small enough as to gurantee that the original surface texture is covered by the process and therefore, must be defined according to the effective area of contact of the burnishing ball with the surface texture features. Therefore, it is normally defined in a preliminary assessment phase before applying the actual VABB. Furthermore, this parameter has a direct impact on productivity, as it is directly responsible for the number of adjacent passes required to cover a certain target area.

5. Feed $f$. It is the linear velocity by which the ball is displaced on the material. Thus far, no infulence on the actual VABB results have been reported in literature, and is therefore a mere productivity parameter.

6. Amplitude of vibration $A$. This parameter is defined by the vibration-assistance system and cannot usually be changed. However, at sight of the previous explanation about acoustoplasticity, it seems that it has to be high enough as to cause a change of the material by means of that effect and guarantee the transmission of the vibratory wave through the material lattice.

7. Frequency of vibration $f_{v}$. As was explained before, it seems that the effects of vibration assistance should be independent of the frequency used in the system to implement it. However, most systems do not allow the user to change this frequency, especially if it is based on resonating principles. For this reason, it is considered a parameter just for those VABB toolings where it can be adjusted, although it should be just kept constant in all cases.

From the explained parameters, the combination of preload, number of passes, trajectories and lateral offset must be defined in the NC routine implemented to apply VABB on the target surface. The former is actually the linear coordinate the ball has to be positioned at to guarantee a certain pressure on the material surface before starting the routine, whereas the three others are programmed through interpolation functions in the ISO code.

The need to define all these parameters before implementing the process is a challenge for those willing to use VABB to improve the finishing routines inside their industries. For this reason, it is necessary to follow a certain strategy to define Jerez-Mesa (2018) [50] defined after extensive work with different materials that a certain protocol has to be defined, and it depends on the alloy that has to be treated and its original surface state. Figure 3 is an extension of what can be consulted on the referenced Thesis Dissertation and it summarizes that protocol. The frequency and amplitude of the system are normally fixed by the VABB tool. Therefore, to apply the process, the user has to take into consideration what is the target material and what is its current topological state. That defines the actual preload and number of passes to be chosen to modify the topology, residual stress and hardness of the surface. On the other hand, the definition of the trajectories and the lateral offset between passes must be decided to define the desired directionality of the surface texture and preferential residual stress component. By defining these parameters, the user shall be able to master the conditions under which VABB must be executed to maximise its results. It should also be note that, in case the VABB process leads to stress relaxation, then the non-assisted process should be considered instead, although probably the adjustment of the processing conditions could lead to an eventual improvement of the effects of VABB. 


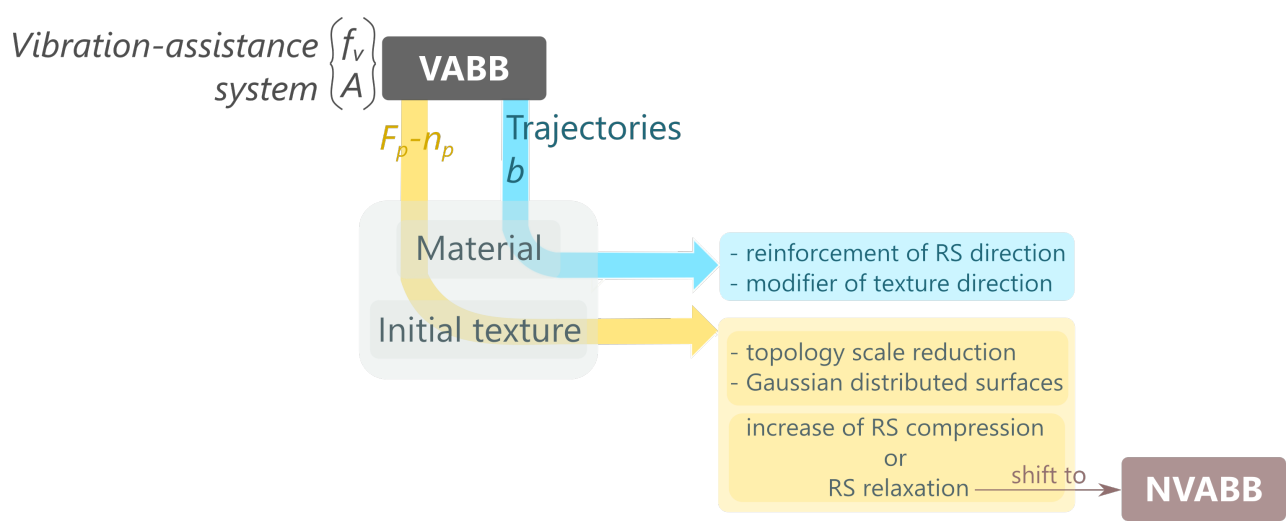

Figure 3. Recommended protocol to be followed to design the VABB processing conditions.

\section{Conclusions and Prospects}

The VABB process featured in this Encyclopedia entry has proved to be a procedure of interest for the industry and researchers during many decades and is starting to be more prominent now with the development of new research activities and the proliferation of practical tooling systems that are easy to manufacture. The best way to technologically implement the process in an actual environment requires a previous testing phase in which the most convenient parameters should be fixed to increase the potential of the process as much as possible and achieve simultaneous effects on texture, residual stress and hardening of the material.

VABB has all the ingredients to be the first option to be adopted as finishing technology in numerous manufacturing environments. However, the prospects of the technology are associated with certain challenges to be tackled that are related to understand the phenomenology behind the physical driver of plastic deformation under the acoustoplastic effect. Extensive experimental research has proved that the results of the process are highly dependant on the interaction of the ball and the original texture. Indeed, the interaction of the vibratory deforming body and the target material is micrometrical, and has proven to be highly influential on the actual results of the process. Increasing the theoretical knowledge of the process not only would lead to the deeper understanding of VABButterly important in the academic field-but could also reduce the timespan of the previous assessment phase referred to previously to plan the actual implementation of the process.

The innovation of the tooling systems to apply the process are also another innovation line to be explored in the future. The most extended systems reported in the literature to apply the actual process have been explained in this entry. However, the high frequency that these instruments vibrate at, and the dynamics of the mechanical system composed by the long tool pressed on the target surface, makes it difficult to monitor de process with conventional acquisition systems. VABB tooling must, therefore, be explored with different techniques so that the effectiveness of its systems are ratified.

All in all, VABB has proven to be an interesting process with some drawbacks in comparison with other direct competitors such as shot peening, but its capability of being applied selectively on specific areas of industrial parts and the easiness of integration in a manufacturing routine have earned it a prominent position in the present and future of finishing techniques.

Funding: Financial support for this study was provided by the Ministry of Science, Innovation and Universities of Spain, through grant RTI2018-101653-B-I00, which is greatly appreciated. Furthermore, by the regional government of Catalonia and FEDER funds for regional development through grant 2019PROD00036.

Acknowledgments: The main author Ramón Jerez-Mesa acknowledges the Serra Hunter programme of the Generalitat de Catalunya.

Conflicts of Interest: The authors declare no conflict of interest. 
Entry Link on the Encyclopedia Platform: https:/ / encyclopedia.pub/11771.

\author{
Abbreviations \\ The following abbreviations are used in this manuscript: \\ NVABB Non-vibration-assisted ball burnishing \\ VABB Vibration-assisted ball burnishing
}

\title{
References
}

1. Downes, K. Finishing of automobile components by rolling. Prod. Eng. 1964, 43, 376-382. [CrossRef]

2. Skelton, R.C. Turning with an oscillating tool. Int. J. Mach. Tool Des. Res. 1968, 8, 239-259. [CrossRef]

3. Tian, Y.; Shin, Y.C. Laser-assisted burnishing of metals. Int. J. Mach. Tools Manuf. 2007, 47, 14-22. [CrossRef]

4. Marakov, A. Ultrasonic diamond burnishing. Russ. Eng. J. 1973, 53, 58-62.

5. Pande, S.; Patel, S. Investigations on vibratory burnishing process. Int. J. Mach. Tool Des. Res. 1984, 24, 195-206. [CrossRef]

6. Bozdana, A.T.; Gindy, N.N.; Li, H. Deep cold rolling with ultrasonic vibrations-A new mechanical surface enhancement technique. Int. J. Mach. Tools Manuf. 2005, 45, 713-718. [CrossRef]

7. Bozdana, A.; Gindy, N. Comparative experimental study on effects of conventional and ultrasonic deep cold rolling processes on Ti-6Al-4V. Mater. Sci. Technol. 2008, 24, 1378-1384. [CrossRef]

8. Huuki, J.; Laakso, S.V. Integrity of surfaces finished with ultrasonic burnishing. Proc. Inst. Mech. Eng. Part B J. Eng. Manuf. 2013, 227, 45-53. [CrossRef]

9. Huuki, J.; Hornborg, M.; Juntunen, J. Influence of Ultrasonic Burnishing Technique on Surface Quality and Change in the Dimensions of Metal Shafts. J. Eng. 2014, 2014, 124247. [CrossRef]

10. Travieso-Rodriguez, J.A.; Gomez-Gras, G.; Dessein, G.; Carrillo, F.; Alexis, J.; Jorba-Peiro, J.; Aubazac, N. Effects of a ballburnishing process assisted by vibrations in G10380 steel specimens. Int. J. Adv. Manuf. Technol. 2015, 81, 1757-1765. [CrossRef]

11. Travieso-Rodríguez, J.A.; Gras, G.G.; Peiró, J.J.; Carrillo, F.; Dessein, G.; Alexis, J.; Rojas, H.G. Experimental study on the mechanical effects of the vibration-assisted ball-burnishing process. Mater. Manuf. Process. 2015, 30, 1490-1497. [CrossRef]

12. Jerez-Mesa, R.; Landon, Y.; Travieso-Rodriguez, J.A.; Dessein, G.; Lluma-Fuentes, J.; Wagner, V. Topological surface integrity modification of AISI 1038 alloy after vibration-assisted ball burnishing. Surf. Coat. Technol. 2018, 349, 364-377. [CrossRef]

13. Jerez-Mesa, R.; Travieso-Rodríguez, J.A.; Landon, Y.; Dessein, G.; Lluma-Fuentes, J.; Wagner, V. Comprehensive analysis of surface integrity modification of ball-end milled Ti-6Al-4V surfaces through vibration-assisted ball burnishing. J. Mater. Process. Technol. 2019, 267, 230-240. [CrossRef]

14. Jerez-Mesa, R.; Plana-García, V.; Llumà, J.; Travieso-Rodriguez, J.A. Enhancing Surface Topology of Udimet ${ }^{\circledR} 720$ Superalloy through Ultrasonic Vibration-Assisted Ball Burnishing. Metals 2020, 10, 915. [CrossRef]

15. Jerez-Mesa, R.; Fargas, G.; Roa, J.J.; Llumà, J.; Travieso-Rodriguez, J.A. Superficial Effects of Ball Burnishing on TRIP Steel AISI 301LN Sheets. Metals 2021, 11, 82. [CrossRef]

16. Salmi, M.; Huuki, J.; Ituarte, I.F. The ultrasonic burnishing of cobalt-chrome and stainless steel surface made by additive manufacturing. Prog. Addit. Manuf. 2017, 2, 31-41. [CrossRef]

17. Teimouri, R.; Amini, S.; Bami, A.B. Evaluation of optimized surface properties and residual stress in ultrasonic assisted ball burnishing of AA6061-T6. Measurement 2018, 116, 129-139. [CrossRef]

18. Amini, S.; Bagheri, A.; Teimouri, R. Ultrasonic-assisted ball burnishing of aluminum 6061 and AISI 1045 steel. Mater. Manuf. Process. 2018, 33, 1250-1259. [CrossRef]

19. Ao, N.; Liu, D.; Liu, C.; Zhang, X.; Liu, D. Face-centered titanium induced by ultrasonic surface rolling process in Ti-6Al-4V alloy and its tensile behavior. Mater. Charact. 2018, 145, 527-533. [CrossRef]

20. Zhao, J.; Liu, Z. Investigations of ultrasonic frequency effects on surface deformation in rotary ultrasonic roller burnishing Ti-6Al-4V. Mater. Des. 2016, 107, 238-249. [CrossRef]

21. Ren, K.; Yue, W.; Zhang, H. Surface modification of Ti6Al4V based on ultrasonic surface rolling processing and plasma nitriding for enhanced bone regeneration. Surf. Coat. Technol. 2018, 349, 602-610. [CrossRef]

22. Zhang, Q.; Hu, Z.; Su, W.; Zhou, H.; Liu, C.; Yang, Y.; Qi, X. Microstructure and surface properties of 17-4PH stainless steel by ultrasonic surface rolling technology. Surf. Coat. Technol. 2017, 321, 64-73. [CrossRef]

23. Shepard, M.J.; Prevey, P.; Jayaraman, N. Effects of Surface Treatment on Fretting Fatigue Performance of Ti-6Al-4V; Technical Report; Air Force Research Laboratory: Dayton, OH, USA, 2004.

24. Amini, C.; Jerez-Mesa, R.; Travieso-Rodriguez, J.A.; Llumà, J.; Estevez-Urra, A. Finite element analysis of ball burnishing on ball-end milled surfaces considering their original topology and residual stress. Metals 2020, 10, 638. [CrossRef]

25. Blaha, F.; Langenecker, B. Dehnung von Zink-Kristallen unter Ultraschalleinwirkung. Naturwissenschaften 1955, 42, 556. [CrossRef]

26. Izumi, O.; Oyama, K.; Suzuki, Y. Effects of superimposed ultrasonic vibration on compressive deformation of metals. Trans. Jpn. Inst. Met. 1966, 7, 162-167. [CrossRef]

27. Izumi, O.; Oyama, K.; Suzuki, Y. On the superimposing of ultrasonic vibration during compressive deformation of metals. Trans. Jpn. Inst. Met. 1966, 7, 158-161. [CrossRef]

28. Langenecker, B. Work hardening of zinc crystals by high-amplitude ultrasonic waves. Proc. Am. Soc. Test. Mat 1962, 62, 602. 
29. Kozlov, A.; Selitser, S. Peculiarities in the plastic deformation of crystals subjected to the acoustoplastic effect. Mater. Sci. Eng. A 1988, 102, 143-149. [CrossRef]

30. Kozlov, A.; Selitser, S. Kinetics of the acoustoplastic effect. Mater. Sci. Eng. A 1991, 131, 17-25. [CrossRef]

31. Langenecker, B. Effects of ultrasound on deformation characteristics of metals. Sonics Ultrason. IEEE Trans. 1966, 13, 1-8. [CrossRef]

32. Gindin, I.; Malik, G.; Neklyudov, I.; Rozumnyi, O. Effect of ultrasonic vibrations on the parameters of the hardening curve for copper single crystals. Sov. Phys. J. 1972, 15, 192-196. [CrossRef]

33. Blaha, F.; Langenecker, B. Plastizitätsuntersuchungen von metallkristallen in ultraschallfeld. Acta Metall. 1959, 7, 93-100. [CrossRef]

34. Mason, W. Effect of Dislocations on Ultrasonic Wave Attenuation in Metals. Bell Syst. Tech. J. 1955, 34, 903-942. [CrossRef]

35. Pohlman, R.; Lehfeldt, E. Influence of ultrasonic vibration on metallic friction. Ultrasonics 1966, 4, 178-185. [CrossRef]

36. Nevill, G.; Brotzen, F.R. The effect of vibrations on the static yield strength of a low-carbon steel. Proc. Am. Soc. Test. Mater. 1957, $57,751-758$.

37. Kirchner, H.; Kromp, W.; Prinz, F.; Trimmel, P. Plastic deformation under simultaneous cyclic and unidirectional loading at low and ultrasonic frequencies. Mater. Sci. Eng. 1985, 68, 197-206. [CrossRef]

38. Tanibayashi, M. A theory of the Blaha effect. Phys. Status Solidi 1991, 128, 83-94. [CrossRef]

39. Malygin, G. Acoustoplastic effect and the stress superimposition mechanism. Phys. Solid State 2000, 42, 72-78. [CrossRef]

40. Siu, K.; Ngan, A.; Jones, I. New insight on acoustoplasticity-Ultrasonic irradiation enhances subgrain formation during deformation. Int. J. Plast. 2011, 27, 788-800. [CrossRef]

41. Siu, K.; Ngan, A. The continuous stiffness measurement technique in nanoindentation intrinsically modifies the strength of the sample. Philos. Mag. 2013, 93, 449-467. [CrossRef]

42. Siu, K.; Ngan, A. Understanding acoustoplasticity through dislocation dynamics simulations. Philos. Mag. 2011, 91, 4367-4387. [CrossRef]

43. Sedláček, R.; Blum, W.; Kratochvil, J.; Forest, S. Subgrain formation during deformation: Physical origin and consequences. Metall. Mater. Trans. A 2002, 33, 319-327. [CrossRef]

44. Siu, K.; Ngan, A. Oscillation-induced softening in copper and molybdenum from nano-to micro-length scales. Mater. Sci. Eng. A 2013, 572, 56-64. [CrossRef]

45. Cheng, B.; Leung, H.; Ngan, A. Strength of metals under vibrations-dislocation-density-function dynamics simulations. Philos. Mag. 2015, 95, 1845-1865. [CrossRef]

46. Liu, Y.; Wang, L.; Wang, D. Finite element modeling of ultrasonic surface rolling process. J. Mater. Process. Technol. 2011, 211, 2106-2113. [CrossRef]

47. Gómez-Gras, G.; Travieso-Rodríguez, J.A.; González-Rojas, H.A.; Nápoles-Alberro, A.; Carrillo, F.J.; Dessein, G. Study of a ball-burnishing vibration-assisted process. Proc. Inst. Mech. Eng. Part B J. Eng. Manuf. 2015, 229, 172-177. [CrossRef]

48. Jerez-Mesa, R.; Travieso-Rodriguez, J.A.; Gomez-Gras, G.; Lluma-Fuentes, J. Development, characterization and test of an ultrasonic vibration-assisted ball burnishing tool. J. Mater. Process. Technol. 2018, 257, 203-212. [CrossRef]

49. Estevez-Urra, A.; Llumà, J.; Jerez-Mesa, R.; Travieso-Rodriguez, J.A. Monitoring of Processing Conditions of an Ultrasonic Vibration-Assisted Ball-Burnishing Process. Sensors 2020, 20, 2562. [CrossRef]

50. Jerez Mesa, R. Study and Characterisation of Surface Integrity Modification after Ultrasonic Vibration-Assisted Ball Burnishing. Ph.D. Thesis, Universitat Politècnica de Catalunya, Barcelona, Spain; Université Toulouse III Paul Sabatier, Toulouse, France, 2018. 